\title{
Koordinasi Mata Tangan TerhadapKemampuan Chest Pass Atlet BolaBasket Sma Pembangunan Laboratorium Padang
}

\author{
Oleh, Frizki Amra \\ Frizki_amra@ rocketmail.com
}

\begin{abstract}
Abstrak
Penelitian ini berawal dari rendahnya kemampuan chest pass atlet SMA Pembangunan Laboratorium Padang. Diprediksi disebabkan oleh rendahnya kondisi fisik koordinasi mata tangan. Penelitian ini bertujuan untuk mengetahui seberapa besar kontribusi koordinasi mata tangan terhadap kemampuanchest pass atlet bolabasket SMA Pembangunan Laboratorium Padang.

Jenis penelitian yang digunakan adalah korelasional. Populasi adalah seluruh atlet putra SMA Pembangunan Laboratorium Padang yang berjumlah 20 orang, penarikan sampel menggunakan teknik total sampling. Data dikumpulkan melalui Test koordinasi mata tangan menggunakan ball werfen und-fangen serta test kemampuan chest pass menggunakan chest passtest. Teknik analisis data denganFmetode statistik regeresi sederhana dan ganda.

Hasil penelitian ini menyatakan bahwa (1) koordinasi mata tangan berkontribusi terhadap kemampuanchest pass sebesar $45,43 \%$

Kata kunci : Koordinasi Mata Tangan, Chest Pass

\section{PENDAHULUAN}

Permainan bola basket diciptakan oleh Dr. James A. Naismith seorang bangsa Amerika yang berkerja sebagai guru pendidikan jasmani pada sekolah perkumpulan orang kristen yaitu YMCA (Young Mans Cristian Association) di Spring field Massachusets Amerika Serikat pada tahun 1891. Dr. james A. Naismith melakukan beeberapa eksperimen dengan merubah dan memasukan ide-ide permainan football, baseball, dan sepak bola. Olahraga bola basket merupakan olahraga permainan yang menuntut permainan cepat, tepat, akurat, dan kerjasama dalam tim. Tujuan dari permainan bola basket yaitu mencetak poin sebanyak-banyaknya dan mampu mempertahankan ring dari serangan lawan.
\end{abstract}




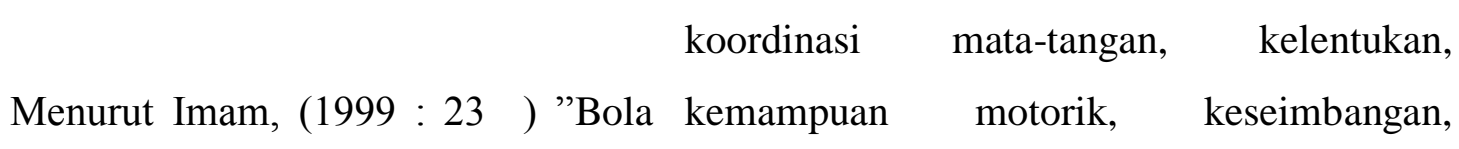
basket merupakan salah satu cabang olahraga kecepatan reaksi, kecepatan gerakan dan prestasi yang terdiri dari berbagai teknik kekuatan otot. Daya ledak merupakan salah dasar yaitu : melempar (passing), menangkap satu komponen fisik yang penting dalam (catching), menggiring (dribbling), segala kegiatan olahraga termasuk dalam menembak (shooting), berlari (start), berhenti melakukan chest pass bola basket.

(stop), penguasaan tubuh (body control),

CorbindalamBasirun

(2006:16) memoros (pivoting), menjaga lawan mengemukakan "daya ledak adalah (guarding), dan gerakan kaki (foot work)". kemampuan untuk menampilkan atau

Passing merupakan salah satu teknik mengeluarkan kekuatan secara eksplosif. yang paling dominan dalam bola basket, Daya ledak mempengaruhi kekuatan dan karena olah raga bola basket merupakan olah kecepatan, baik kecepatan rangsangan raga tim maka kerjasama dan operan-operan maupun kecepatan kontraksi otot. Daya ledak bola merupakan faktor penting dalam meraih tidak hanya ditentukan oleh kekuatan kemenangan. Ditinjau dari perjalanan bola kontraksi otot saja, tetapi juga ditentukan pada saat mengoper, ada beberapa macam oleh jarak dan jumlah otot yang berkontraksi teknik dasar passing yang sering digunakan setiap menitnya”. Daya ledak mempunyai yaitu: operan tolakan dada ( chest pass ), peranan penting, artinya dalam permainan operan dari atas kepala ( over head pass) bola basket elemen kondisi ini merupakan dan operan pantulan ( bounce pass )". komponen yang menentukan dalam gerakan

Dari semua jenis passing, chest pass chest pass. Tanpa kondisi dimaksud, tubuh merupakan passing paling sering digunakan. tidak dapat meproyeksikan arah gerakan Jenis operan ini dilakukan dengan secara cepat dan tepat. menolakkan bola dari depan dada kepada teman dengan cepat dan arah bola mendatar setinggi dada. Karena chest pass merupakan operan yang mementingkan kecepatan dan ketepatan dalam pelaksanaannya, jadi sangat berperan sekali dalam melakukan serangan cepat tanpa mudah disergap lawan.

Agar chest pass dapat dilakukan dengan baik, banyak faktor yang mempengaruhi, diantaranya : daya ledak otot lengan,

\section{TINJAUAN PUSTAKA}

\section{Chest Pass}

Istilah passing dalam permainan bola basket berarti mengoper bola kepada teman, seperti dikemukakan oleh Adnan (1999:28)Chest pass adalah “operan yang dilakukan dengan arah mendatar dan penerimaan bola pada teman jaga diusahakan setinggi dada". Sedangkan Amber (1995:25) menyatakan bahwa “Teknik 
mengoper bola setinggi dada ini disebut bola langkahkan satu kaki kedepan yang demikian, karena memang bola dilemparkan kemudian diikuti gerakan lanjutan kaki setinggi dada pemain". Dalam menguasai berikutnya setelah bola lepas.

bola hendaknya bola dekat dengan dada, posisi siku tangan berada di samping badan dan dekat pada tangan (tidak terbuka).

Dari pendapat diatas jelaslah Chest pass bukan merupakan passing yang dilakukan dari atas kepala, tetapi Chest pass adalah passing dilakukan dari se tinggi dada (dari depan dada) dan ke arah dada penerima passing atau target tertentu setinggi dada. Dalam Chest pass ini pada umumnya dilakukan dua belah tangan dengan menolakan bola dari arah dada dan bukan dilemparkan dengan sebelah tangan.

Operan dua tangan merupakan yang sangat penting dan sering dilakukan dalam permainan bola basket, operan ini sangat bermanfaat untuk operan jarak panjang maupun jarak pendek, demi memperhitungkan ketepatan dan kecepatan. Terutama pada saat teman yang menerima bola tidak di jaga ketat atau tidak dikawal degan ketat.

Chest pass mengandung prinsip mengarahkan bola mendatar se tinggi dada, bola hendaknya dekat dengan dada, posisi tangan berada di samping badan dan dekat dengan badan gunakan jari-jari tangan dan bola dilontarkan yang diikuti oleh gerakan lanjutan tangan lurus kedepan saat bola lepas. Agar adanya keseimbangan tubuh dan kekuatan operan bersamaan dengan lontaran
Dalam melakukan passing dada tersebut otot kerangka yang berperan adalah otot kerangka bagian atas yaitu semua otot lengan mulai dari otot pergelangan lengan bawah sampai dengan otot pergerakan pergelangan tangan dan jari. Adapun namanama otot tersebut adalah deltoideus, coracobrachialis, biceps brachii berkepala pendek, brachialis, tendon, supinator, scapula, brachioradialis, pronatorteres, ulna, radius, tricep brachii kepala panjang, humerus, phalanges, flexor digitorum superficialis, dan bayak lagi otot yang terlibat.

\section{Koordinasi Mata-Tangan}

Banyak para ahli yang menjelas mengenai koordinasi, diantaranya menurut Jhonath dalam Ricel (2005 : 9) menyatakan "koordisasi adalah kerja sama antara susunan syaraf pusat dengan otot yang dilibatkan dalam suatu konraksi”. Syafruddin (1999 : 62) menjelaskan "koordinasi merupakan kemampuan untuk menjelaskan tugas-tugas motorik secara cepat dan terarah yang ditentukan oleh proses pengendalian dan pengaturan gerakan serta kerja sama sistem persyarafan pusat".

$$
\text { Menurut Yanuar (1999 }
$$

"koordinasi gerak adalah hubungan timbal balik antara pusat susunan syaraf dengan alat 
gerak dalam mengatur dan mengendalikan melakukan gerakan dengan dihubungkan impuls tenaga dan kerja otot serta proses- oleh sytem syaraf.

proses motorik yang terjadi untuk Effendi dalam Ricel (2005:11) pelaksanaan gerak". Senada dengan itu, mengemukan bahwa "informasi sensorik Aryance (2006 : 35) menyebutkan yang datang berupa ransangan, "koordinasi merupakanhubungan kerja sama diintegrasikan pada berberapa tingkat dari antara susunan syaraf pusat dengan alat gerak susunan syaraf pusat dan menimbulkan reaksi saat berkontraksi dalam menyelesaikan tugas- motorik yang dibutuhkan". Saat melakukan tugas motorik". Sedangkan Hirts dalam chest pass, diawali oleh mata yang melihat Erianti (2004:43) menerangkan "koordinasi untuk menerima ransangan yang kemudian merupakan kemampuan yang ditentukan oleh mengirimnya keotak melalui persyarafan. proses pengendalian dan pengaturan Setelah ituotak menyimpulkan informasi gerakan".

tersebut dan kemudian memberikan perintah

Dalam bola basket, peranan koordinasi kepada tangan untuk melakukan gerakan mata-tangan sangat dominan, salah satunya melalui syaraf-syaraf otot lengan.

pada saat melakukan chest pass. Bagus atau

Dari urain di atas dapat disimpulkan tidaknya koordinasi mata-tangan seseorang bahwa koordinasi mata-tangan merupakan ditentukan oleh beberapa faktor antara lain : kerja sama susunan syaraf mata dan susunan kemampuan intelegensi, ketepatan organ syaraf tangan dalam melakukan tugas sensorik, pengalaman motorik dan tingkat motorik dengan efisien melalui perantara kemampuan biomotor lainnya. Namun system syaraf pusat. Dalam melakukan chest demikian, menurut Bachtiar (1999: 163) pass koordinasi mata-tangan sangat berperran "kemampuan koordinasi mata-tangan sekali, karena saat mau melakukan passing, seseorang dapat ditingkatkan dengan latihan terlebih dahulu seseorang harus kombinasi gerakan yang dimulai dari gerakan memperhatikan teman atau sasaran yang mudah ke yang sulit dan latihan yang lemparan, apakah waktunya sudah tepat dan dapat meningkatkan kerja syaraf otot dan teman telah siap menerima operan kita. indra".

Setelah waktunya tepat, barulah kita

Dalam melakukan chest pass, melakukan chest passtersebut. Oleh karena koordinasi mata-tangan sangat berpengaruh itu sangat dibutuhkan sekali koordinasi yang karena mata merupakan alat optik yang baik antara mata dan tangan agar operan tepat berfungsi untuk penglihatan dan tangan sasaran. Jika tidak ada koordinasi antara mata merupakan alat gerak bagian atas. Kedua dan tangan maka sudah pasti operan tersebut bagian tubuh ini bekerja sama dalam tidak akan tapat sasaran. 


\section{Metode Penelitian}

Penelitian ini termasuk jenis penelitian korelasional yaitu penelitian ini bertujuan mencari tahu seberapa besar kontribusi koordinasi mata-tangan terhadap kemampuan chest pass.

\section{Teknik Pengumpulan Data}

Data ini didapatkan melalui tes two hand medicine ball put untuk mengukur daya ledak otot lengan, ball werfen und-fangen untuk mengukur koordinasi mata-tangandan kemampuan chest pass diukur dengan memantulkan bola basket ke dinding selama 15 detik.

\section{Instrumen Penelitian}

\section{a. Koordinasi Mata-Tangan}

Menurut Winarno dalam Erianti (2009 : 46 ), untuk mengukur koordinasi mata-tangan menggunakan tes ball werfen und-fangen, dengan koefisien reliabilitas $0,78 . \quad$ Dalam mengumpulkan data ini membutuhkan alat antara lain :

1. 1 buah bola tenis

2. Dinding sebagai sasaran lemparan

3. Kapur sebagai penggaris

4. 1 buah stopwacth

5. 1 buah meteran
6. Blangko penilain dan alat tulis

Sedangkan untuk pelaksanaannya sebagai berikut :

1. Testee (siswa) mengambil posisi lempar di belakang garis lempar yang berjarak 2 meter dari dinding sasaran dengan memegang bola

2. Setelah aba-aba "ya" testee melakukan lemparan kedinding dengan satu tangan berulang kali selama 15 detik

3. Lemparan dilakukan dengan satu tangan melalui atas bahu kemudian menangkap pantulan bola dengan tangan yang lain dan kaki tidak boleh menginjak garis batas lemparan

4. Pelaksanaan dilakukan hanya 1 kali percobaan

5. Cara menskor adalah jumlah bola yang tertangkap dengan benar dan masuk ke dinding sasaran 


\section{b. Kemampuan Chest Pass}

Untuk mengukur kemampuan chest pass dalam permainan bola basket digunakan Keterangan: tes memantulkan bola ke dinding tembok, dengan ketentuan :

1. Tujuan tes ini untuk mengukur kemampuan hasil chest pass

2. Alat dan perlengkapan Untuk satu stasiun dibutuhkan satu bola basket, satu sasaran pada dinding tembok yang rata, satustopwatch, formulir perorangan dan alat tulis

3. Pengetes

Untuk satu stasiun dibutuhkan tiga orang pengetes

1. Pengetes waktu 1(satu) orang

2. Pengawas 1(satu) orang

3. Pencatat 1 (satu) orang

4. Pelaksanaan

Pada aba-aba "siap" testee (siswa) berdiri dibelakang garis batas (e), menghadap kearah sasaran atau dinding tembok ke daerah sasaran A, sambil memegang bola dengan kedua tangan

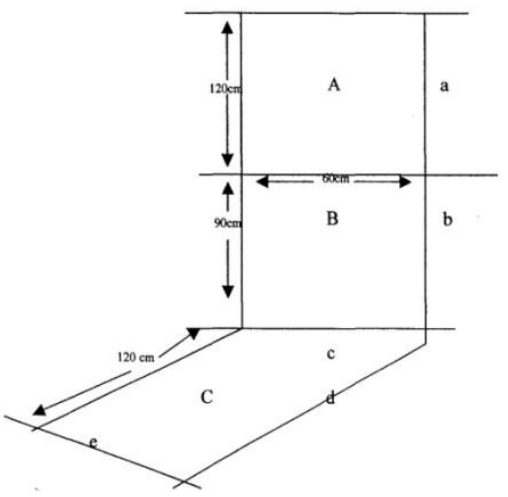

A- Adalah daerah sasaran dengan ukuran $60 \times 120$ $\mathrm{cm}$

B- Adalah daerah di bawah daerah sasaran dan berukuran $60 \mathrm{x}$ $90 \mathrm{~cm}$

C- Adalah lantai (rata), jarak antara dinding tembok dengan garis (e) ialah $160 \mathrm{~cm}$

a- Jarak garis $\mathrm{f}$ dan garis g adalah $120 \mathrm{~cm}$

b- Jarak garis c dan garis $\mathrm{f}$ adalan 90 $\mathrm{cm}$

c- Ialah garis batas antara garis tembok dan lantai dengan ukuran $\quad 60 \mathrm{~cm}$ Jarak antara diding tembok degan garis batas e dengan ukuran $160 \mathrm{~cm}$. 


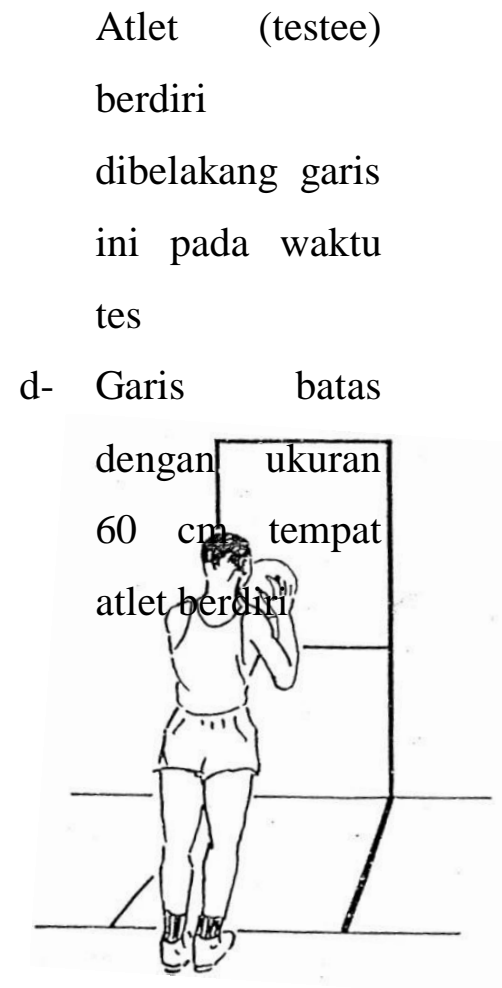

an bola

sebanyak

mungkin

dalam

waktu 15

(lima belas)

detik.

2. Apa bila

tidak dapat

dikuasainya

dan

menggelind

ing jauh

dari garis

batas e,

maka atlet

(testee)

Pelaksanaan :

mengambil

1. Pada aba-

bola

aba "YA"

tersebut,

bola

kemudian ia

dipantulkan

segera

kearah

kembali ke

sasaran A,

belakang

bola

garis batas

ditangkap

(e) untuk

dan

melanjutka

dipantulkan

$\mathrm{n}$

tes

kembali.

sampai

Demikian

batas waktu

seterusnya

yang

atlet (testee)

ditentukan

berusaha

habis.

memantulk 
3. Bagi

pengambil

waktu,

bersama

aba-aba

"YA"

stopwatch

dijalankan

4. Aba-aba

"STOP"

diberikan

tepat pada

detik ke 15

(lima belas)

dan

stopwatch

dihentikan

5. Pada waktu

atlet (testee)

melakukan

tes,

pengawas

mengamati

pantulan

bola pada

sasaran A

dan

menghitung

berapa kali yang digunakakn adalah teknik analisis

atlet dapat korelasi dan regeresi sederhana dan ganda.

mematulka Menurut Hadi (1996 : 37) Hipotesis satu

$\mathrm{n}$ bola dianalisis dengan korelasi dan regresi

kesasaran formula product moment melalui program

Hasil yang dicatat adalah jumlah pantulan bola yang sah pada dinding sasaran A selama 15 (lima belas) detik

Catatan:

a. Pada

palaksanaan

"tes"

memantulkan

bola pada

dinding tembok

ini, bola tidak

boleh di-volley

b. Pantulan yang

sah adalah

apabila bola

dipantulkan /

passing ke

dinding dengan

dua tangan dari

belakang garis

batas e dan

mengenai

sasaran A atau

batas daerah

sasaran A

\section{Teknik Analisis Data}

Teknik dan prosedur analisis data

5. Pencatat hasil

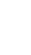


SPSS (Statistical Product an Service Solution For Windows) versi 11.

Sebelum menggunakan analisis regresi ganda dan korelasi sederhana, perlu konstan dilakukan uji persyaratan analsis yaitu uji normalitas seberan dengan menggunakan uji arah korelasi linear liliefors, uji linearitas dan uji lenearitas korelasional melalui program SPSS, selanjutnya dilakukan uji independen antar variabel bebas.

$$
\frac{N \sum x y-\left(\sum x\right)\left(\sum y\right)}{\sqrt{\left[n \sum x^{2}-\left(\sum x\right)^{2}\left[n \sum y^{2}-\left(\sum y\right)^{2}\right]\right.}}
$$

Keterangan : Rxy $=$ koefisien korelasi yang dihitung

$$
\sum x=\text { jumlah }
$$

produck skor $\mathrm{x}$

$$
\sum x^{2} \quad=\text { jumlah }
$$

kuadarat produck skor butir

$$
\sum y \quad=\text { jumlah skor }
$$

produck y

$$
\sum y^{2}=\text { jumlah }
$$

kuadrat produck skor butir

$$
\sum x y=\text { jumlah }
$$

produck skor $\mathrm{x}$ dikali jumlah produck skor $\mathrm{y}$

( Arikunto, 1997)

$$
\mathrm{Y}=\mathrm{a}+\mathrm{b} 1 . \mathrm{X} 1+\mathrm{b} 2 . \mathrm{X} 2
$$

Keterangan $: \mathrm{Y}=$ variabel jriterium

\section{A. Deskripsi Data} setiap variabel. pada tabel di bawah ini.

$$
\mathrm{X}=\text { variabel }
$$

prediktor

$\mathrm{a}=$ bilangan

$\mathrm{b}=$ koefisien

\section{HASIL PENELITIAN DAN PEMBAHASAN}

Data penelitian ini terdiri dari : Kemampuan Chest Pass (Y) sebagai variabel terikat, Koordinasi Mata Tangan $\left(\mathrm{X}_{1}\right)$. Untuk masing-masing variabel di bawah ini akan disajikan nilai rata-rata, simpangan baku, distribusi frekuensi, serta histogram dari

\section{Koordinasi Mata Tangan (X1)}

Berdasarkan data penelitian untuk skor koordinasi mata tangan, didapatkan data bahwa skor terendah 8 dan skor tertinggi 15 . Dari analisis data diperoleh harga rata-rata (Mean)sebesar 11,3, dan Simpangan baku (standar deviasi) 2,13. Distribusi frekuensi koordinasi mata tangan sebagaimana tampak

Tabel 1. Distribusi Frekuensi

Koordinasi Mata Tangan

\begin{tabular}{|c|c|c|c|}
\hline No. & Kelompok Skor & $\begin{array}{c}\text { Frekuensi } \\
\text { Absolut }\end{array}$ \\
\hline 1. & $8-9$ & 6 & \\
\hline
\end{tabular}




\begin{tabular}{|c|c|ccc|}
\hline 2. & $10-11$ & 3 & (standar 15deviasi) & sebesar \\
\hline 3. & $12-13$ & 7 & $2,15$. Distribusi5 frekuen\$i & untuk \\
\hline 4. & $14-15$ & 4 & kemampuan 2best pass dapat dilihat \\
\hline & Total & 20 & pada tabel di poovah ini. & \\
\hline
\end{tabular}

Berdasarkan perhitungan yang tertera pada tabel di atas dapat dilihat bahwa: 6 orang atau ( $30 \%$ ) berada di kelompok skor $8-9,3$ orang atau (15\%) berada di kelompok skor 10 11, 7 orang atau $(35 \%)$ berada di kelompok skor 12 - 13, 4 orang atau (20\%) berada di kelompok skor 14 15. Untuk lebih jelasnya, distribusi frekuensi kelentukan juga dapat dilihat pada histogram di bawah ini :

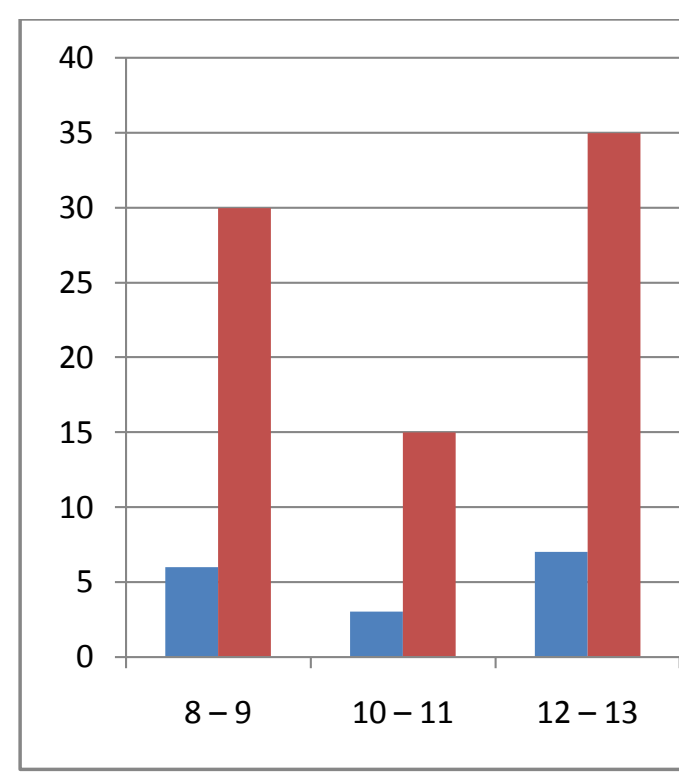

\section{Kemampuan Chest Pass (Y)}

Berdasarkan data penelitian untuk skor kemampuan chest pass diperoleh skor terendah 23 dan skor tertinggi 30. Dari analisis data diketahui skor rata-rata (mean) sebesar 27,7, dan simpangan baku
Tabel 2. Distribusi Frekuensi

Kemampuan Chest Pass

\begin{tabular}{|c|c|c|c|}
\hline No. & Kelompok Skor & $\begin{array}{c}\text { Frekuensi } \\
\text { Absolut }\end{array}$ \\
\hline 1. & $21-22$ & 0 & 4 \\
\hline 2. & $23-24$ & 4 & 8 \\
\hline 3. & $25-26$ & 4 & \\
\hline 4. & $27-28$ & 20 & \\
\hline 5. & $29-30$ & Total & \\
\hline & &
\end{tabular}

Berdasarkan perhitungan yang tertera pada tabel di atas dapat dilihat bahwa : 0 orang atau ( $0 \%$ ) berada di kelompok skor 21 - 22, 4 orang atau (20\%) berada di kelompok skor $23-24,4$ orang atau $(20 \%)$ berada di kelompok skor $25-26,8$ orang atau (40\%) berada di kelompok skor 27 28 , dan 4 orang atau (20\%) berada di kelompok skor 29 - 30. Untuk lebih jelasnya, distribusi frekuensi kemampuan pukulan smashjuga dapat dilihat pada histogram di bawah ini : 


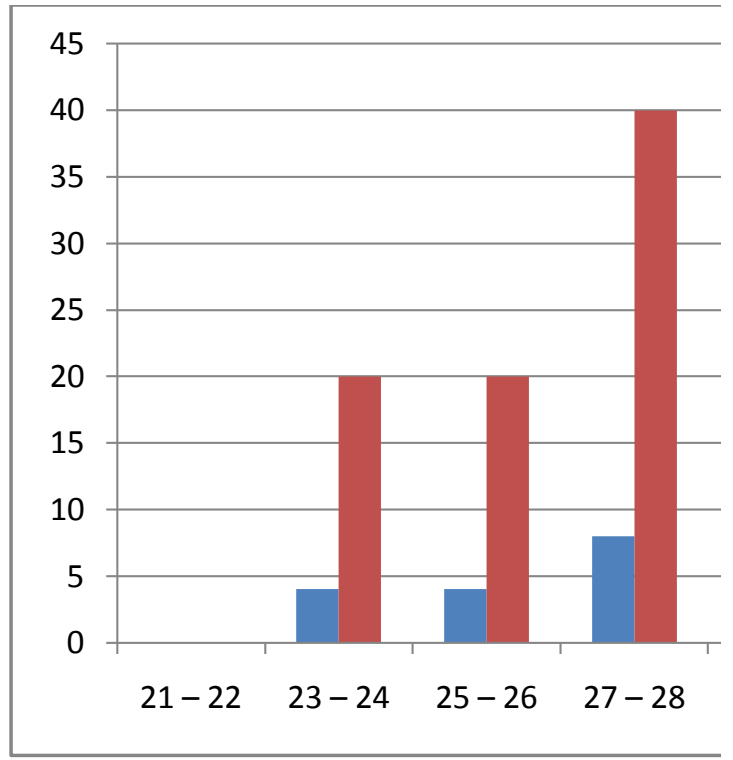

\section{B. Pengujian Persyaratan Analisis}

Persyaratan analisis yang dimaksud adalah persyaratan yang harus dipenuhi sebelum melakukan analisis korelasi. Persyaratan analisis tersebut meliputi Uji Normalitas dan Uji Hipotesis yaitu sebagai berikut :

\section{Uji Normalitas}

Data yang diperoleh dari hasil pengukuran Koordinasi Mata Tangan, kelentukan dan kemampuan pukulan smash terlebih dahulu dilakukan uji normalitas dengan uji Liliefors. Berdasarkan uji normalitas diperoleh harga $\mathrm{L}_{0}$ dan $\mathrm{L}_{\mathrm{t}}$ pada taraf nyata 0,05 untuk $\mathrm{n}=20$. Kriteria pengujian $\mathrm{L}_{0}<$ $\mathrm{L}_{\mathrm{t}}$ maka sampel berasal dari populasi yang terdistribusi normal. Hasil analisis uji normalitas data masingmasing variabel di sajikan dalam Tabel di bawah ini;
Tabel 3. Uji Normalitas

\begin{tabular}{|c|c|c|}
\hline \multicolumn{1}{|c|}{ Variabel } & Lo & $\mathrm{L}_{\mathrm{tab}}$ \\
\hline Koordinasi Mata Tangan & 0.1291 & 0.19 \\
\hline Kemampuan Chest Pass & 0.0694 & 0.19 \\
\hline \multicolumn{2}{|c|}{ Tabel di atas menunjukkan }
\end{tabular}

bahwa untuk Koordinasi Mata Tangan $\left(\mathrm{X}_{1}\right)$ diperolehLo $=0.1291$ sedangkan $\mathrm{L}_{\text {tabelpada }}$ taraf signifikan $\alpha=0.05$ diperoleh 0.190. Jadi Lo $<\mathrm{L}_{\text {tabel }}$ berarti data berdistribusi secara normal. Untuk KemampuanChest Pass (Y) diperolehLo $=0.0694$,

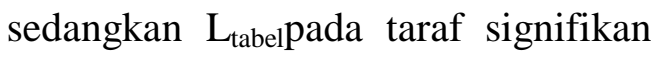
$\alpha=0,05$ diperoleh 0.190. Jadi Lo $<$ $\mathrm{L}_{\text {tabel }}$ berarti data berdistribusi secara normal.

Berdasarkan uraian diatas dapat disimpulkan bahwa data variabel $\mathrm{X}_{1}$ dan $\mathrm{Y}$ memiliki $\mathrm{L}_{0}<\mathrm{L}_{\mathrm{t}}$, hal ini berarti data ketiga variabel berdistribusi normal.

\section{Pengujian Hipotesis}

Hipotesis yang di uji dalam penelitian ini adalah terdapatnya hubungan yang signifikan antara Koordinasi Mata Tangandengan kemampuanchest pass, berdasarkan hasil analisis data didapat $\mathrm{r}_{\text {hitung }}=$ 0.714 .

Tabel 4. Rangkuman Hasil Analisis 


\begin{tabular}{|c|c|c|c|}
\hline $\mathbf{r}_{\text {hitung }}$ & $\mathbf{r}$ tabel & taraf signifikan & Keterangan Analisis korelasi terhadap koordinasi \\
\hline 0.674 & 0.444 & $\alpha=0.05$ & Signifikata tangan dengan kemampuan chest pass \\
\hline 0.706 & 0.444 & $\alpha=0.05$ & Signifikanghasilkan koefisien korelasi sebesar $\mathrm{r}_{\mathrm{y} 1}$ \\
\hline
\end{tabular}

Dari tabel diatas dapat dilihat di bawah ini.

bahwa terdapat hubungan yang signifikan antara koordinasi mata tangan terhadap kemampuan chest pass, $\mathrm{r}_{\text {hitung }}$ lebih besar dari pada $\mathrm{r}_{\text {tabel }}$ dimana $r_{\text {hitung }}=0.674>r_{\text {tabel }}=0.444$.

Jadi hipotesis yang diajukan terdapat hubungan yang signifikan terbukti kebenarannya dengan $\alpha=$ 0.05 .

\section{Pembahasan}

Berdasarkan dari hasil analisis data dan pengujian hipotesis penelitian, berikut ini dikemukakan pembahasan terhadap pengujian hipotesis tersebut.

\section{Kontribusi antara Koordinasi Mata} Tangan $\left(X_{1}\right)$ dengan Kemampuan Chest Pass(Y) Atlet Bola Basket SMA Pembangunan Laboratorium

\section{Padang}

Untuk menguji hipotesis penelitian ini, maka dilakukan analisis korelasi product moment dengan hipotesis sebagai berikut :

$\mathrm{H}_{\mathrm{O}}$ : Tidak terdapat hubungan yang signifikan antara $\mathrm{X}_{1}$ dengan $\mathrm{Y}$

$\mathrm{H}_{\mathrm{a}}$ : Terdapat hubungan yang signifikan antara $\mathrm{X}_{1}$ dengan $\mathrm{Y}$
Tabel 5. Hasil Analisis Korelasi Antara Koordinasi Mata Tangan (X) dan Kemampuan Chest Pass(Y)

\begin{tabular}{|c|c|c|}
\hline $\begin{array}{c}\text { Korelasi } \\
\text { Antara }\end{array}$ & $\begin{array}{c}\text { Koefisien } \\
\text { Korelasi } \\
(\mathrm{r})\end{array}$ & $\mathrm{t}_{\text {hitung }}$ \\
\hline $\mathrm{X}_{2}$ dan $\mathrm{Y}$ & 0,674 & 3.87 \\
\hline
\end{tabular}

Keterangan:

Koefisien korelasi signifikan $t_{\text {hit }}(3.87)$ $>t_{\text {tab }}(1.73)$

Berdasarkan uji keberartian korelasi antara pasangan skor koordinasi mata tangan $\left(\mathrm{X}_{2}\right)$ dengan kemampuan chest pass sebagaimana terlihat pada tabel di atas diperoleh $t_{\text {hitung }}(3.87)>t_{\text {tabel }}$ (1.73) pada taraf signifikansi $\alpha=0,05 \mathrm{dan} \mathrm{dk}$ (n-2=18). Jadi, dapat diketahui bahwa Ho ditolak dan Ha diterima. Dengan demikian terdapat hubungan yang signifikan antara koordinasi mata tangan dengan kemampuan chest pass atlet bola basket SMA Pembangunan Laboratorium Padang. 
Dan Kontribusi antara

Koordinasi Mata Tangan $\left(\mathrm{X}_{1}\right)$ dengan

Kemampuan chest pass (Y) atlet bola

basket SMA Pembangunan

Laboratorium Padang adalah sebesar:

$45,43 \%$.

\section{Kesimpulan}

Berdasarkan hasil penelitian yang telah diuraikan pada bab-bab terdahulu dapat dikemukakan kesimpulan sebagai berikut:

1. Hasil yang peroleh dari Koordinasi Mata Tanganmempunyai hubungan yang signifikan terhadap Kemampuan Chest Pass. Ditandai dengan hasil yang diperroleh yaitu rhitung 0,674> rtabel 0,444

2. Hasil perhitungan koefisien determinan dari variabel Koordinasi Mata Tangan berkontribusi terhadap Kemampuan Chest Pass sebesar $45,43 \%$. 